\title{
AKUT KORONER SENDROM HASTALARINDA, OBSTRÜKTIF UYKU APNE SENDROMUNUN DEĞERLENDIRILMESI
}

\section{EVALUATION OF OBSTRUCTIVE SLEEP APNEA SYNDROME IN PATIENTS WITH ACUTE CORONARY SYNDROME}

Mevlüt Serdar KUYUMCU1, Fatih ÖKSÜZ²

${ }^{1}$ Isparta Süleyman Demirel Üniversitesi Kardiyoloji Kliniği

2 Ankara Eğitim Araştırma Hastanesi Kardiyoloji Kliniŏi

Cite this article as: Kuyumcu MS, Öksüz F. Evaluation Of Obstructive Sleep Apnea Syndrome In Patients With Acute Coronary Syndrome. Med J SDU 2020; 27(1): 39-44.

\section{Öz}

\section{Amaç}

Obstrüktif uyku apne sendromu (OSAS) kardiyovasküler hastalıklar ile yakın ilişki içindedir. Basitleştirilmiş OSAS diyagnostik metodolojilerinin değerlendirilmesi halen yenidir ve kardiyoloji alanında derinlemesine araştırılmamıştır. Bu çalışmada, ülkemizdeki akut koroner sendrom (AKS) hastalarında OSAS ilişkisini ve koroner arter hastalığı ciddiyeti ilişkisini, SYNTAX skoru, Berlin Uyku Anketi (BUA) ve Epworth Uykululuk Ölçeği (EUÖ) kullanarak değerlendirmeyi amaçladık.

\section{Gereç ve Yöntem}

Akut koroner sendrom ile başvuran ve koroner anjiyografi yapılan 160 hasta çalışmaya dahil edildi $[n=80$ ST segment yükselmeli myokard infaktüsü (STEMi) ve $n=80$ ST segment yükselmesiz myokard infaktüsü (NSTEMI)]. Hastaların SYNTAX skorları hesaplandı. Hastalara taburculuk öncesi (BUA) ve (EUÖ) uygulandı. Ölçekler iki grup arasında ve hastaların SYNTAX skoru ile kıyaslandı.

\section{Bulgular}

NSTEMi hastalarında BUA ve EUÖ'ye göre yüksek riskli hasta oranı STEMI grubuna göre istatiksel olarak anlamlı saptanmıştır $(p<0.001, p=0.023)$. BUA ve EUÖ'de saptanan toplam puan miktarları NSTEMi hastalarında STEMi grubuna göre istatiksel olarak anlamlı saptanmıştır $(p<0.001)$. Pearson korelasyon analizinde SYNTAX skoru ile BUA'da saptanan toplam puan arasında ve SYNTAX skoru ile EUÖ arasında anlamlı pozitif korelasyon saptanmıştır $(r=0.865$, $p<0.001$ ve $r=0.761, p<0.001$ )

\section{Sonuç}

Bu çalışmada, OSAS ve AKS arasındaki ilişki değerlendirilmiştir. BUA ve EUÖ ölçeği sonuçları literatüre göre yüksek saptanmıştır ve SYNTAX skoru ve OSAS riski arasında pozitif korelasyon saptanmıştır.

Anahtar Kelimeler: Obstrüktif uyku apne sendromu, akut koroner sendrom, SYNTAX skoru.

\section{Abstract}

\section{Objective}

Obstructive sleep apnea syndrome (OSAS) is closely associated with cardiovascular diseases. Evaluation of simplified OSAS diagnostic methodologies is still new and has not been deeply investigated in the field of cardiology. In this study, we aimed to evaluate the relationship between OSAS and the severity of coronary artery disease in our patients with acute coronary syndrome (ACS), using the SYNTAX score, the Berlin Sleep Questionnaire (BUA) and the Epworth Sleepiness Scale (EUÖ).

İletişim kurulacak yazar/Corresponding author: kuyumcuserdar@hotmail.com

Müracaat tarihi/Application Date: 26.09.2018 • Kabul tarihi/Accepted Date: 19.10.2018

Available online at http://dergipark.gov.tr/sdutfd

Makaleye http://dergipark.gov.tr/sdutfd web sayfasından ulaşılabilir. 


\section{Material and Methods}

200 patients with acute coronary syndrome who underwent coronary angiography were enrolled in the study. SYNTAX scores of the patients were calculated. Patients were administered BUA and EUÖ before discharge. The scales were compared between the two groups and with SYNTAX scores of patients.

\section{Results}

In NSTEMI patients, the rate of high-risk patients in the BUA and ACL was statistically significant compared to the STEMI group $(p<0.001, p=0.023)$. The total score of the BUA and the total score in the EUÖ was statistically significant in NSTEMI patients compared to the STEMI group $(p<0.001)$. Pearson correlation analysis revealed a significant positive correlation between the SYNTAX score and the total score in the BUA and between the SYNTAX score and the EUÖ ( $r$ $=0.865, p<0.001$ ve $r=0.761, p<0.001$ )

\section{Conclusions}

In this study, the relationship between OSAS and ACS was evaluated. The results of the BUA and EUÖ scale were higher than those of other countries and a positive correlation was found between SYNTAX score and OSAS risk.

Keywords: Obstructive sleep apnea syndrome, acute coronary syndrome, SYNTAX score.

Iışmaya dahil edildi. Hastaların tedavileri tamamlandıktan sonra taburcu olacakları gün literatürde en çok kullanılan BUA ve EUÖ kullanıldı(5, 6). EUÖ, gündüz uyku halini göstermek için kullanılan bir testtir (Şekil 1). Sekiz sorudan oluşur. Her soruya hasta tarafından 0-3 puan vererek doldurulur. Tüm sorularda uykuya dalma olasılığı hiç yoksa 0 , düşük ise 1 , orta ise 2 ve yüksek ise 3 puan alır. Toplam puan 10 ve üzerinde ise gündüz aşırı uyku halinin varlığına işaret eder. BUA, OSAS toplum taramaları için düzenlenmiş bir ankettir (Şekil). Toplam 3 kategoride 10 soru bulunmaktadır. Kategori 1 ve 2'de $\geq 2$ puan ve kategori 3'te $\geq 1$ puan anlamlı kabul edilir. Her kategori kendi içerisinde değerlendirilerek 2 veya daha fazla kategori pozitif çıkarsa OSAS riski yüksek kabul edilir. Hasta kayıtları ve hastanenin otomasyon sistemi kullanılarak hastaların yaş, kilo, boy, boyun çevresi, bel çevresi öğrenildi. Hipertansiyon en az iki ölçümle sistolik kan basıncının $\geq 140 \mathrm{mmHg}$ ve/veya diyastolik kan basıncının $\geq 90 \mathrm{mmHg}$ saptanması veya aktif olarak antihipertansif ilaç kullanımı olarak tanımlandı. Diabetes mellitus, açlık plazma glukoz düzeyi $6.9 \mathrm{mmol} / \mathrm{l}$ üzerinde veya herhangi bir ölçümde $11.1 \mathrm{mmol} / \mathrm{l}$ üzerinde glikoz seviyesi saptanması veya antidiyabetik ilaç kullanımı olarak tanımladı. Hiperlipidemi, 11.1 $\mathrm{mmol} / \mathrm{l}$ veya daha yüksek total kolesterol düzeyleri veya statin kullanımı öyküsü olarak tanımlandı. Hastaneye yatmadan önce sigara içen hastalar sigara içen olarak kabul edildi. Ciddi kalp kapak hastalığı, akut romatizmal ateş öyküsü, prostetik kapağı, dekompanse kalp yetmezliği, malignitesi, böbrek veya karaciğer disfonksiyonu, akut veya kronik inflamatuar hastalığı, hematolojik hastalığı ve kronik obstrüktif akciğer hastalığı olan hastalar çalışma dışı bırakıldı. Çalışma Helsinki Deklarasyonu'nda belirtilen ilkelere uygundur ve yerel kurumsal etik komitesi tarafından onaylanmıştır. 
Hastaların koroner anjiyografisi femoral yada radial arter yolu kullanılarak Judkins tekniği (Siemens Axiom Artis Zee 2011; Siemens Healthcare, Erlangen, Germany) ile yapılmıştır. Her koroner arter en az 2 pozisyonda değerlendirilmiştir. Bu koroner anjiyografi sonucuna göre SYNTAX skoru, hastaların klinik veya laboratuvar sonuçlarından habersiz deneyimli girişimsel kardiyolog tarafından tüm hastalar için hesaplandı. SYNTAX skoru, SYNTAX skor hesaplayıcısı 2.1'e (www.syntaxscore.com) göre> 1.5 mm'lik bir damarda>\% 50 çap darlığı olan tüm koroner lezyonlar için belirlendi.
İstatistiksel analizler SPSS 20.0 (Statistical Package for Windows, Chicago, Illinois, USA) programı ile yapıldı. Verilerin normal dağılımını incelemek amacıyla Kolmogorov- Smirnov testi kullanıldı. Sayısal değişkenlerden normal dağılım sergileyenler (parametrik)

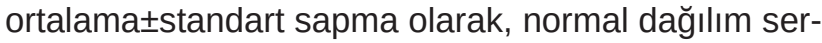
gilemeyenler (non-parametrik) ise ortanca medyan) değer olarak (beraberinde çeyrekler arası aralık ile) ve kategorik değişkenler yüzde olarak belirtildi. Sayısal değişkenler için Student-t testi veya Mann-Whitney U-testi, kategorik değişkenlerin analizi için ki-kare testi kullanılmıştır. p<0.05 olan değişkenler için anlamlı kabul edilmiştir.

Şekil 1: Berlin Anketi Soruları ve Değerlendirilmesi
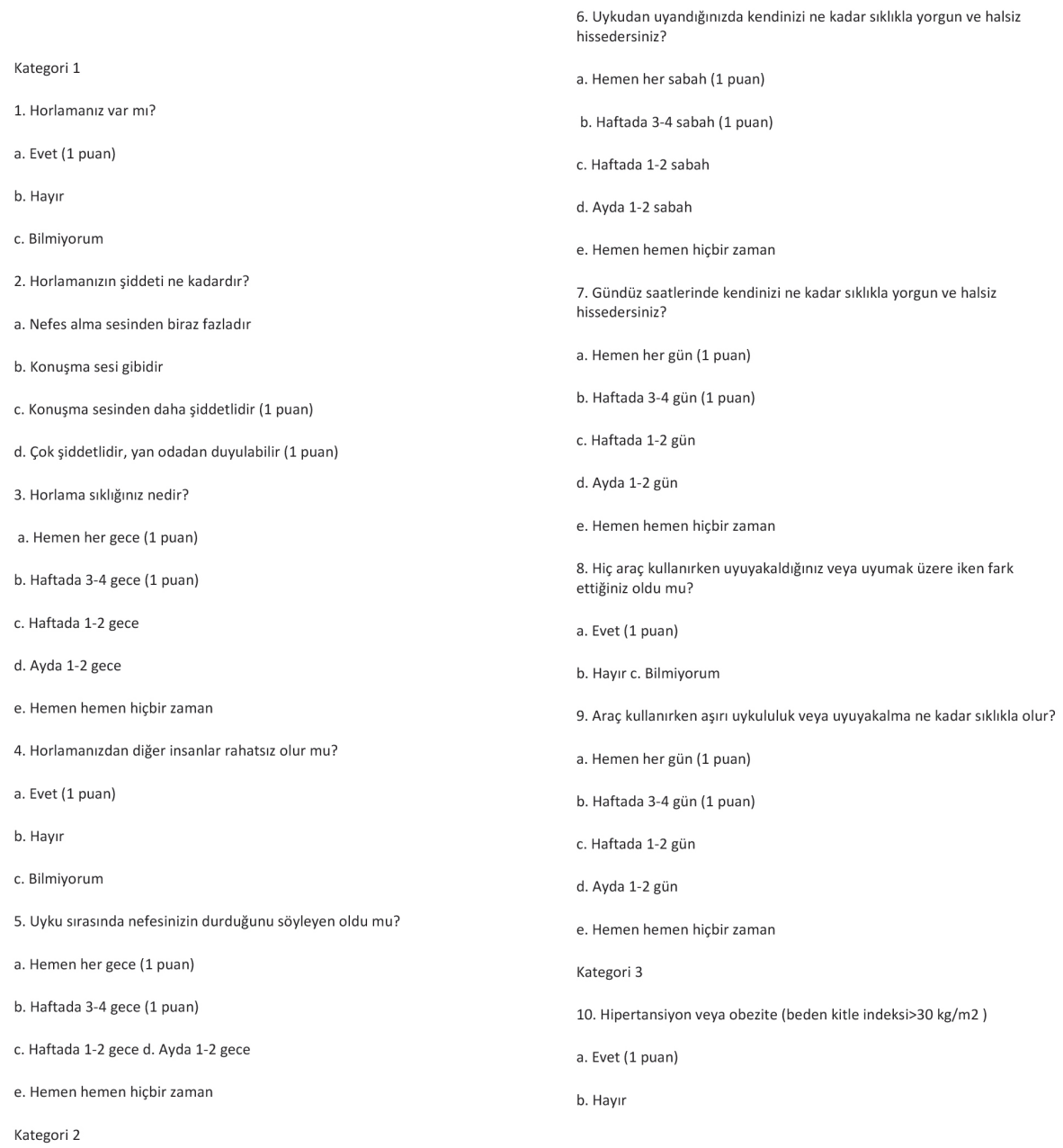

Berlin Anketi Puanlama Yöntemi

\begin{tabular}{lll} 
& Anlamlı Puan & Sonuç \\
\hline Kategori 1 & $\geq 2$ & 3 Kategoriden 2 veya daha fazlası $(+)$ ise yüksek risk \\
Kategori 2 & $\geq 2$ & \\
Kategori 3 & $\geq 1$ &
\end{tabular}


Şekil 2: Epworth Uykululuk Ölçeği.

Gündüz uyku halini göstermekte kullanılan bir testtir. Toplam 8 sorudan oluşur. Her soru hastanın kendisi tarafından 0-3 puan verilecek şekilde doldurulur. $\mathrm{Bu}$ ankette hastanın aşırı yorgun olmadığı sıradan bir günde, belli durumlarda uykuya dalma olasılığı sorgulanır. Tüm sorularda puanlama yöntemi aynı olup, uykuya dalma olasılığı hiç yoksa 0 , uykuya dalması düşük olasılıklı ise 1, orta olasılıklı ise 2 ve yüksek olasılıklı ise 3 puan alır. Toplam puan 10 ve üzerinde ise gündüz aşırı uyku halinin varlığına işaret eder.

Şekil 3: Berlin Uyku Anketi ve SYNTAX Skoru korelasyon analizi

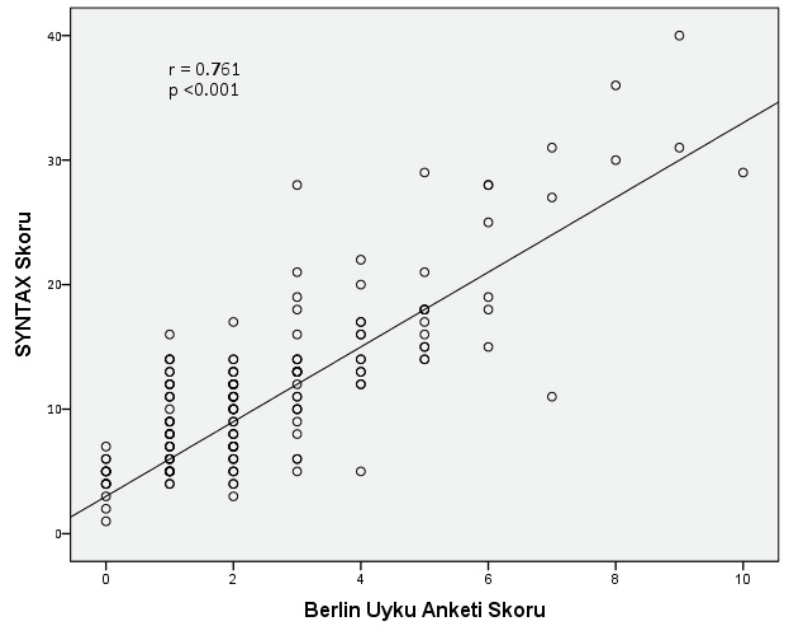

\section{Sonuç}

Çalışma gruplarının bazal özellikleri ve laboratuar parametreleri Tablo 1'de gösterilmiştir. ST segment yükselmesiz myokard infaktüsü (NSTEMi) grubunda, ST segment yükselmesiz myokard infaktüsü (STEMi) grubuna göre diabetes mellitus, hipertansiyon ve ailede kalp hastalığı öyküsü oranları daha yüksek saptanmıştır ancak istatiksel olarak anlamlı bulunamamıştır. NSTEMi grubunda, STEMi grubuna göre beden kitle indeksi, boyun ve bel çevre seviyeleri daha yüksek saptanmıştır ancak ancak istatiksel olarak anlamlı bulunamamıştır. NSTEMi grubunda, STEMi grubuna göre ortalama SYNTAX skoru ve ejeksiyon fraksiyonu oranları daha yüksek saptanmıştır $(p<0.001)$.

NSTEMi hastalarında EUÖ’ ye göre yüksek riskli hasta oranı STEMi grubuna göre istatiksel olarak anlamIı saptanmıştır $(p=0.023)$. EUÖ'de saptanan toplam puan miktarıda NSTEMi hastalarında STEMI grubuna göre istatiksel olarak anlamlı saptanmıştır $(p<0.001)$. NSTEMi hastalarında BUA' ya göre yüksek riskli hasta oranı STEMi grubuna göre istatiksel olarak anlam-

\section{Sorular}

Aşırı yorgun olmadığınız bir günde aşağıdaki durumlarda uykuya dalma olasılığınız nedir?

1. Oturur durumda gazete veya kitap okurken

2. Televizyon seyrederken

3. Pasif olarak toplum içinde otururken (tiyatro, toplantı,...)

4. Aralıksız 1 saatlik araç yolculuğu yaparken

5. Öğleden sonra uzanınca

6. Alkolsüz bir öğle yemeğinden sonra otururken

7. Birisi ile konuşurken

8. Araç kullanırken birkaç dakika trafik durduğu

Şekil 4: Epworth Uykululuk Ölçeği ve SYNTAX Skoru korelasyon analizi

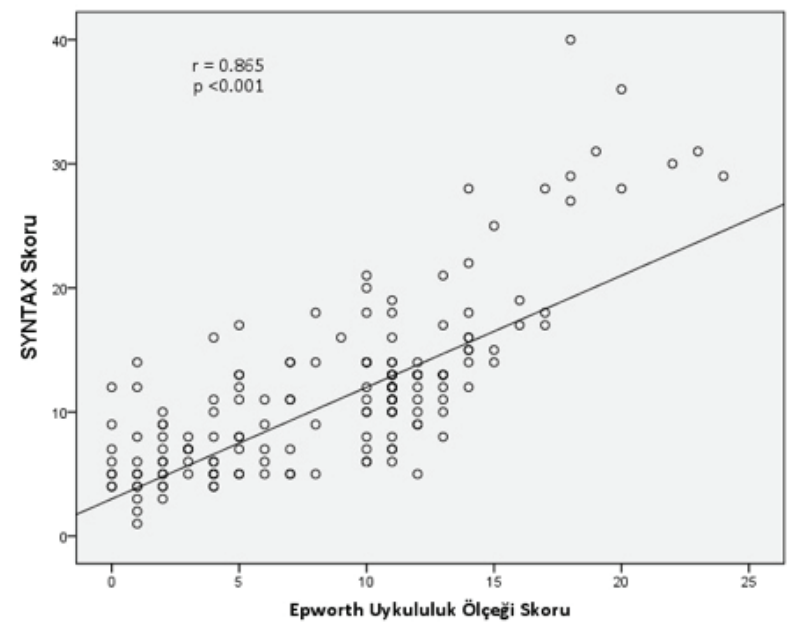

Iı saptanmıştır $(p<0.001)$. BUA'da saptanan toplam puan miktarıda NSTEMi hastalarında STEMi grubuna göre istatiksel olarak anlamlı saptanmıştır $(p<0.001)$.

Pearson korelasyon analizinde SYNTAX skoru ile BUA'da saptanan toplam puan arasında ve SYNTAX skoru ile EUÖ arasında anlamlı pozitif korelasyon saptanmıştır $(r=0.644, p<0.001$ ve $)$

\section{Tartışma}

Çalışmamızda NSTEMI grubunda OSAS' a yatkınlığın yüksek olduğu saptanmıştır. Literatürde ilk defa SYNTAX skoru ve OSAS riski arasında pozitif korelasyon saptanmıştır.

Kardiyovasküler hastalıklarda en önemli risk faktörlerinden biri artmış sempatik aktivitedir(9). Hayvan modellerinden ve insan çalışmalarından elde edilen bulgular, OSAS'ın artmış sempatik aktivasyonla ilişkili olduğuna dair birçok kant bulunmaktadır. Ratlarda yapılan bir deneyde, deneklerin 14-30 gün boyunca aralıklı hipoksiye maruz kalması, katekolaminlerin artmış üretimi ve kan basıncının önemli ölçüde yükselmesi 


\begin{tabular}{|l|l|l|l|}
\hline Değişkenler & NSTEMi (n=80) & STEMi $(\mathbf{n = 8 0})$ & p değeri \\
\hline Yaş & $60.1 \pm 4.5$ & $59.5 \pm 4.4$ & 0.733 \\
\hline BKi, kg/m2 & $29.2 \pm 12.0$ & $28.5 \pm 12.0$ & 0.355 \\
\hline Bel çevresi, cm & $90.31 \pm 8.63$ & $87.13 \pm 5.24$ & 0.401 \\
\hline Boyun çevresi, cm & $37.36 \pm 3.08$ & $35.91 \pm 3.20$ & 0.658 \\
\hline Erkek cinsiyet, $\mathrm{n}(\%)$ & $50(62.5)$ & $54(67.5)$ & 0.507 \\
\hline Diabetes mellitus, $\mathrm{n}(\%)$ & $31(38.8)$ & $22(27.5)$ & 0.131 \\
\hline Hipertansiyon, $\mathrm{n}(\%)$ & $37(46.3)$ & $27(33.8)$ & 0.107 \\
\hline Hipelipidemi, $\mathrm{n}(\%)$ & $30(37.5)$ & $25(31.3)$ & 0.405 \\
\hline Sigara, $\mathrm{n}(\%)$ & $34(42.5)$ & $38(47.5)$ & 0.525 \\
\hline Ailede kalp hastalı̆̆ı öyküsü & $34(42.5)$ & $24(30.0)$ & 0.100 \\
\hline EUÖ toplam puan & $10.9 \pm 5.3$ & $6.2 \pm 4.6$ & $<0.001$ \\
\hline EUÖ yüksek riskli hasta oranı & $38(47.5)$ & $24(33.8)$ & 0.023 \\
\hline BUA toplam puan & $3.1 \pm 1.6$ & $1.8 \pm 1.3$ & $<0.001$ \\
\hline BUA yüksek riskli hasta oranı & $37(46.3)$ & $22(27.5)$ & $<0.001$ \\
\hline SYNTAX skoru & $14.7 \pm 7.8$ & $7.7 \pm 4.2$ & $<0.001$ \\
\hline Ejeksiyon Fraksiyonu & $52 \pm 6.8$ & $43 \pm 10.8$ & $<0.001$ \\
\hline
\end{tabular}

ile ilişkili bulunmuştur(10). Ayrıca ratlarda, kronik aralıklı hipoksinin, renin-anjiyotensin sistemi aracılığıyla kemorefleks ile uyarılmış sempatik çıkış akımını arttırdığı izlenmiştir(11).Deneysel bir randomize kontrollü çalışma, aralıklı hipoksinin vasküler sistem üzerindeki etkilerine ilişkin veri sağlamıştır. Bu çalışmada, 10 sağlıklı erkek, aralıklı hipoksiye veya günde 6 saat süreyle sahte bir prosedüre maruz kalmıştır; 4 gün aralıklı hipoksiden sonra ortalama kan basıncı $4 \mathrm{mmHg}$ artmıştır ve nitrik oksit türevleri\% 55 oranında azalmıştır, bu da baskıda artış ve hipoksiye serebral vasküler direnç cevabı ile ilişkili bulunmuştur(12). Artmış sempatik aktivite ile tutarlı olarak, OSAS hastalarında yapılan bir çalışmada, hastalarda yüksek seviyelerde periferik sinir aktivitesi, plazma norepinefrin ve idrar katekolaminleri gözlenmiştir(13).

Endotel disfonksiyonu AKS patofizyolojisinde kilit noktalardan birdir(14).OSAS'ın endotel disfonksiyonu ile ilişkili olduğuna ve azalmış endotel onarım kapasitesine sebebiyet verdiğine dair çalışmalar bulunmaktadır. Yapılan bir çalışmada OSAS'ı hastalarda, asetilkolinin intra-arteriyel infüzyonu sonrasında önkol kan akımı ile ölçülen endotel bağımlı vazodilatasyon, normal kontrol grubuyla karşılaştırıldığında bozulmuştur(15). Ayrıca, endotel onarım kapasitesini korumak için gerekli olan dolaşımdaki nitrik oksit ve endotelyal proge- nitör hücrelerin seviyeleri OSAS'lı hastalarda azalmıştır(16).

Koroner arter hastalığı ciddiyeti derecesi ve inflamasyon arasında da yakın ilişki bulunmaktadır(17). Yapılan in-vitro çalışmalarda aralıklı hipoksinin hücre kültürü modellerinde, sürekli hipoksinin aksine, nükleer faktör kappa-B'nin (nF-kB) aracılı inflamatuar yolların, hipoksi-indüklenebilir faktör (HiF) -1-bağımlı yolaklar üzerinde tercihen aktive edildiğini göstermiştir(18). Ayrıca çok sayıda kesitsel, vaka kontrol ve randomize olmayan girişimsel çalışmaların bulguları, proinflamatuar sitokin IL-6 ve C-reaktif proteinin düzeylerinin osaslı hastalarda yükseldiğini ve OSAS tedavisi ile azaldığını ortaya koymuştur(19, 20). Dolayısı ile OSAS'ın koroner arter hastalığı patofizyolojisinde inflamasyon yolu ile rol oynama potansiyeli bulunmaktadır.

Çalışmamız sonunda bulunan BUA ve EUÖ ölçeği sonuçları Polonya ve Çin'de yapılan çalışmalara göre daha yüksek sonuçlarda çıkmıştır $(7,8)$. Bu popülasyonlarla çalışma gurbumuz kıyaslandığında ortalama BKI ve eşlik eden diabetes mellitus gibi komorbitideler bizim çalışma grubumuzda daha fazla saptanmıştır dolayısı ile bizim çalışma grubumuzda BUA ve EUÖ ölçeği sonuçlarının daha yüksek çıkması bu şekilde 
açıklanabilir. Çalışmamızda NSTEMi hastalarında, STEMi hastalarına göre BUA ve EUÖ ölçeği sonuçları daha yüksek saptanmıştır. NSTEMi hastalarında, STEMi hastalarına göre diabetes mellitus, hipertansiyon, obezite gibi komorbiditeler daha sık saptanmaktadır ve bu komorbiditeler OSAS ile yakın ilişki içindedir(21).

Çalışmamızda bulunan başka önemli bir bulgu BUA ve EUÖ ölçeği sorularına verilen, OSAS lehine olan toplam cevap sayısı, SYNTAX skoru ile pozitif korelasyon göstermiştir. SYNTAX skoru, koroner arter hastalığı ciddiyeti saptanmasında altın standarttır(22). Koroner arter hastalarında SYNTAX skoru arttıkça total mortalite ve morbiditenin arttığı izlenmiştir. Bu bulgu literatürde ilk defa gösterilmiştir.

Çalışmamızın bulguları bazı sınırlamalar ile yorumlanmalıdır. Örneklem büyüklüğü göreceli olarak kısıtlıdır ve OSAS ön tanısı altın standart olan uyku testleri kullanılmadan değerlendirilmiştir. Ayrıca hastaların uzun süre takibi yapılmamış ve kardiyovasküler sonlanım noktaları tayin edilmemştir

Bu çalışmada, OSAS ve AKS arasındaki ilişki değerlendirilmiştir. BUA ve EUÖ ölçeği sonuçları diğer ülke popülasyonlarına göre yüksek saptanmıştır ve SYNTAX skoru ve OSAS riski arasında pozitif korelasyon saptanmıştır. Çalışma sonuçları AKS ile tedavisi düzenlenen ya da koroner arter hastalığı ile takip edilen hastalarda OSAS riskinin göz önünde bulundurulması gerektiğini göstermektedir. Ancak bu hipotezi açıklığa kavuşturmak için çok merkezli, geniş ölçekli, randomize ve prospektif çalışmalar gereklidir.

\section{Kaynaklar}

1. Speir WA, Jr., Chaudhary BA. Cardiovascular consequences of sleep apnea. Journal of the Medical Association of Georgia. 1982;71(10):721-2.

2. Lyons OD, Bradley TD. Heart Failure and Sleep Apnea. The Canadian journal of cardiology. 2015;31(7):898-908.

3. Kushida CA, Littner MR, Morgenthaler T, Alessi CA, Bailey D, Coleman J, Jr., et al. Practice parameters for the indications for polysomnography and related procedures: an update for 2005. Sleep. 2005;28(4):499-521.

4. de Oliveira ACT, Martinez D, Vasconcelos LFT, Cadaval Goncalves S, do Carmo Lenz M, Costa Fuchs S, et al. Diagnosis of obstructive sleep apnea syndrome and its outcomes with home portable monitoring. Chest. 2009;135(2):330-6.

5. Netzer NC, Stoohs RA, Netzer CM, Clark K, Strohl KP. Using the Berlin Questionnaire to identify patients at risk for the sleep apnea syndrome. Annals of internal medicine. 1999;131(7):48591.

6. Izci B, Ardic S, Firat H, Sahin A, Altinors M, Karacan I. Reliability and validity studies of the Turkish version of the Epworth Sleepiness Scale. Sleep \& breathing = Schlaf \& Atmung. 2008;12(2):161-8.

7. Jia S, Zhou YJ, Yu Y, Wu SJ, Sun Y, Wang ZJ, et al. Obstructive sleep apnea is associated with severity and long-term progno- sis of acute coronary syndrome. Journal of geriatric cardiology : JGC. 2018;15(2):146-52

8. Szymanski FM, Filipiak KJ, Hrynkiewicz-Szymanska A, Karpinski G, Opolski G. Clinical characteristics of patients with acute coronary syndrome at high clinical suspicion for obstructive sleep apnea syndrome. Hellenic journal of cardiology : HJC = Hellenike kardiologike epitheorese. 2013;54(5):348-54.

9. Manfrini O, Pizzi C, Trere D, Fontana F, Bugiardini R. Parasympathetic failure and risk of subsequent coronary events in unstable angina and non-ST-segment elevation myocardial infarction. European heart journal. 2003;24(17):1560-6.

10. Dematteis M, Julien C, Guillermet C, Sturm N, Lantuejoul S, Mallaret $\mathrm{M}$, et al. Intermittent hypoxia induces early functional cardiovascular remodeling in mice. American journal of respiratory and critical care medicine. 2008;177(2):227-35.

11. Prabhakar NR, Kumar GK, Nanduri J. Intermittent hypoxia-mediated plasticity of acute $\mathrm{O} 2$ sensing requires altered red-ox regulation by HIF-1 and HIF-2. Annals of the New York Academy of Sciences. 2009;1177:162-8.

12. Foster GE, Brugniaux JV, Pialoux V, Duggan CT, Hanly PJ, Ahmed SB, et al. Cardiovascular and cerebrovascular responses to acute hypoxia following exposure to intermittent hypoxia in healthy humans. The Journal of physiology. 2009;587(Pt 13):3287-99.

13. Somers VK, Dyken ME, Clary MP, Abboud FM. Sympathetic neural mechanisms in obstructive sleep apnea. The Journal of clinical investigation. 1995;96(4):1897-904.

14. Veerasamy M, Bagnall A, Neely D, Allen J, Sinclair H, Kunadian V. Endothelial dysfunction and coronary artery disease: a state of the art review. Cardiology in review. 2015;23(3):119-29.

15. Kato M, Roberts-Thomson P, Phillips BG, Haynes WG, Winnicki M, Accurso V, et al. Impairment of endothelium-dependent vasodilation of resistance vessels in patients with obstructive sleep apnea. Circulation. 2000;102(21):2607-10.

16. El Solh AA, Akinnusi ME, Baddoura FH, Mankowski CR. Endothelial cell apoptosis in obstructive sleep apnea: a link to endothelial dysfunction. American journal of respiratory and critical care medicine. 2007;175(11):1186-91.

17. Kundi H. Syntax score and inflammation. Herz. 2016;41(6):5356.

18. Ryan S, Taylor CT, McNicholas WT. Selective activation of inflammatory pathways by intermittent hypoxia in obstructive sleep apnea syndrome. Circulation. 2005;112(17):2660-7.

19. Yokoe T, Minoguchi K, Matsuo H, Oda N, Minoguchi H, Yoshino $\mathrm{G}$, et al. Elevated levels of C-reactive protein and interleukin-6 in patients with obstructive sleep apnea syndrome are decreased by nasal continuous positive airway pressure. Circulation. 2003;107(8):1129-34.

20. Kokturk O, Ciftci TU, Mollarecep E, Ciftci B. Elevated C-reactive protein levels and increased cardiovascular risk in patients with obstructive sleep apnea syndrome. International heart journal. 2005;46(5):801-9.

21. Prejean SP, Din M, Reyes E, Hage FG. Guidelines in review: Comparison of the 2014 AHA/ACC guideline for the management of patients with non-ST-elevation acute coronary syndromes and the 2015 ESC guidelines for the management of acute coronary syndromes in patients presenting without persistent ST-segment elevation. Journal of nuclear cardiology : official publication of the American Society of Nuclear Cardiology. 2018;25(3):769-76.

22. Farooq V, Serruys PW, Bourantas C, Vranckx P, Diletti R, Garcia Garcia HM, et al. Incidence and multivariable correlates of long-term mortality in patients treated with surgical or percutaneous revascularization in the Synergy between Percutaneous Coronary Intervention with Taxus and Cardiac Surgery (SYNTAX) trial. European heart journal. 2012;33(24):3105-13. 